\title{
Flexural Skin
}

National Cancer Institute

\section{Source}

National Cancer Institute. Flexural Skin. NCI Thesaurus. Code C62447.

A crease in the skin on the flexor side of a joint. 